\title{
Ingestão Dietética, Concentrações Séricas e Teciduais Orais de Carotenoides em Pacientes com Carcinoma Epidermoide da Cavidade Oral e da Orofaringe
}

Dietary Intake, Serum Concentrations, and Oral Tissue Concentrations of Carotenoids in Patients with Oral Cavity and Oropharyngeal Cancer Ingesta Dietética, Concentraciones Séricas y Tisulares Bucales de Carotenoides en Pacientes con Carcinoma Epidermoide de Cavidad Bucal y Orofaringe

Regiane Maio', José Carlos Berto², Camila Renata Corrêa ${ }^{3}$, Álvaro Oscar Campana ${ }^{4}$, Sérgio Alberto Rupp Paiva ${ }^{5}$

\section{Resumo}

Com o objetivo de caracterizar pacientes com cânceres da cavidade oral e da orofaringe, quanto à ingestão alimentar e às concentraçôes de carotenoides no soro e tecido oral, foi realizado estudo transversal envolvendo 37 pacientes homens e 11 mulheres, com idade entre 39 e 77 anos, sem tratamento anterior da doença. As biópsias orais foram obtidas durante o ato cirúrgico em todos pacientes. Determinaçâo tecidual de carotenoides foi realizada por Cromatografia Líquida de Alta Eficiência (CLAE), utilizando a coluna C18. As ingestóes dietéticas habituais diárias de carotenoides foram 3.859, 1.994, 1.345, 508, 102 e $78 \mu \mathrm{g} / \mathrm{dia}$ para o total de carotenoides, licopeno, betacaroteno, luteína/ zeaxantina, alfacaroteno e betacriptoxantina, respectivamente. As maiores concentraçóes de carotenoides no soro foram verificadas para o licopeno $(0,54 \mu \mathrm{mol} / \mathrm{L})$ e a luteína/zeaxantina $(0,31 \mu \mathrm{mol} / \mathrm{L})$. No tecido normal, as concentraçóes encontradas foram 3,49; 1,15; 0,12 e 0,09 $\mu \mathrm{mol} / \mathrm{kg}$ para a luteína/zeaxantina, licopeno, betacaroteno e betacriptoxantina, respectivamente; esses valores não foram estatisticamente diferentes em relação aos do tecido neoplásico. O licopeno foi o carotenoide predominante na dieta (53\%) e no soro (45\%). Nos tecidos, houve predomínio da luteína/zeaxantina (64\%-65\%). Correlaçóes significativas ( $r=0,28$ a r=0,70), entre os valores de carotenoides na dieta, no soro e tecido oral, foram observadas para a maioria dos carotenoides. O licopeno foi identificado como o principal carotenoide na dieta e no soro, enquanto a luteína/zeaxantina predominou no tecido oral. Não foi observada depleção dos carotenoides investigados no tecido oral neoplásico no grupo estudado.

Palavras-chave: Carotenoides; Tecidos; Mucosa Bucal; Neoplasias Bucais; Ingestão de Alimentos; Estudos Transversais

Departamento de Clínica Médica da Faculdade de Medicina, Universidade Estadual Paulista (UNESP), Botucatu (SP), Brasil.

${ }^{1}$ Professor Adjunto do Departamento de Nutrição da Universidade Federal de Pernambuco (UFPE), Recife (PE), Brasil.

${ }^{2}$ Mestre pelo Hospital Heliópolis (HOSPHEL) e especialista em cirurgia pela UNESP, Botucatu (SP), Brasil.

${ }^{3}$ Doutora em Patologia. Departamento de Clínica Médica - Laboratório Experimental da Faculdade de Medicina da UNESP, Botucatu (SP), Brasil.

${ }^{4}$ Professor Emérito do Departamento de Clínica Médica da Faculdade de Medicina da UNESP, Botucatu (SP), Brasil.

${ }^{5}$ Professor Adjunto do Departamento de Clínica Médica da Faculdade de Medicina da UNESP, Botucatu (SP), Brasil.

Endereço para correspondência: Regiane Maio. Universidade Federal de Pernambuco. Departamento de Nutrição. Av. Prof. Moraes Rego, 1.235. Cidade

Universitária. Recife (PE), Brasil. CEP: 50670-901. E-mail: regmaio@yahoo.com.br 


\section{INTRODUÇÃO}

Os carotenoides são um grupo de mais de 600 pigmentos (não contando com seus isômeros), existentes na natureza e responsáveis por algumas das cores características das plantas, hortaliças, frutas e animais. Dos 40 tipos de carotenoides encontrados em nossa alimentação, os predominantes são o licopeno, a luteína/ zeaxantina, a betacriptoxantina, o alfacaroteno e o betacaroteno. Estudos epidemiológicos mostram existir relaçáo inversa entre o risco de vários tipos de câncer e a ingestão alimentar ou a concentraçáo sanguínea dos carotenoides ${ }^{1}$.

Além de seu possível papel em relação à prevenção do câncer, existem evidências de que os carotenoides são importantes no tratamento dessa doença. Em vários tipos de câncer, seu poder antiproliferativo é observado em estudos em cultura de células neoplásicas, em modelos animais de carcinogênese induzida, e em estudos clínicos. Por exemplo, o betacaroteno, o licopeno e a luteína mostram-se eficazes na fase de iniciação e/ou nas fases de promoçáo e/ou progressão do câncer, em carcinomas de pele, de fígado, de próstata, e da cavidade oral, induzidos em animais ${ }^{1,2}$. Vários mecanismos de ação anticarcinogênicos são atribuídos aos carotenoides, sendo o de ação antioxidante amplamente aceito. Outros mecanismos de proteção são a atividade vitamínica $\mathrm{A}$, a ação modulatória da comunicação célula a célula, e a ação imunomoduladora. Também é descrito que os carotenoides podem atuar no aumento da diferenciaçáa de células normais e no aumento da apoptose em células neoplásicas ${ }^{1}$. Como esses mecanismos de ação protetora podem estar ocorrendo em tecidos, a disponibilidade dos carotenoides, no tecido oral, é de interesse para a saúde.

Embora sejam disponíveis dados de ingestão alimentar e de concentração sanguínea de carotenoides, não há estudos publicados sobre a concentração dos carotenoides mais comuns em tecido oral neoplásico e não neoplásico obtido por biópsia, em pacientes com cânceres da cavidade oral e da orofaringe. O objetivo deste estudo foi caracterizar um grupo de pacientes com carcinoma epidermoide da cavidade oral e da orofaringe quanto à ingestão alimentar e às concentraçóes dos carotenoides no soro e no tecido normal e neoplásico da cavidade oral. Pretendeu-se, pois, descrever o estado nutricional deste grupo relacionado aos carotenoides.

\section{MATERIAIS E MÉTODOS}

Foi realizado estudo transversal, no qual foram incluídos 48 pacientes com cânceres da cavidade oral e da orofaringe atendidos pelo Serviço de Cirurgia de Cabeça e Pescoço do Hospital Amaral Carvalho em Jaú (SP). Os dados foram coletados no período de maio de 2001 a novembro de 2002. Para composição da casuística, formada a partir de pacientes atendidos em ambulatório, consideraramse os seguintes critérios de inclusão: 1) indivíduos com idade igual ou maior a 20 anos, de qualquer sexo e raça; 2) casos novos (sem nenhum tipo de tratamento prévio da doença); 3) tumores malignos primários do tipo epidermoide confirmados histologicamente; 4) indivíduos em qualquer estágio clínico da doença (estádios de 0 a IV). A participaçáo no estudo foi voluntária, após obtenção do consentimento dos pacientes. A pesquisa foi conduzida após aprovação pelo Comitê de Ética em Pesquisa da Faculdade de Medicina de Botucatu, Unesp (Ofício n²34/2000), em obediência à Resolução 196/96 sobre "Pesquisa envolvendo Seres Humanos", do Conselho de Saúde do Ministério da Saúde. Todos os pacientes participantes do estudo realizaram avaliaçáo laboratorial geral, compreendendo glicemia, exames das funçóes hepática e renal e hemograma. Os seguintes critérios de exclusão foram considerados: presença concomitante de insuficiência renal crônica terminal, cardiopatia, hepatopatia e pneumopatia graves, glicemia de jejum $\geq 126$ $\mathrm{mg} / \mathrm{dL}$ e pacientes em uso recente de polivitamínicos.

Dos pacientes estudados, 37 foram do sexo masculino e 11, do feminino. A faixa etária foi de 39 a 77 anos, sendo a média 56 anos de idade. O grupo constituiu-se predominantemente de indivíduos da raça branca $(98 \%)$. Quanto à distribuição da localização do tumor primário, o acometimento da língua ( $2 / 3$ anteriores) por neoplasia foi mais frequente e ocorreu em $35,4 \%$ dos casos; o câncer de assoalho de boca foi o seguinte mais prevalente (25\%); o restante dos pacientes apresentou cânceres na área retromolar $(12,5 \%)$, palato duro $(8,3 \%)$, regiáo jugal $(2,2 \%)$ e palato mole $(10,4 \%)$. O acometimento dos dois sítios (língua e assoalho bucal) ocorreu em três casos (6,3\%). Com relação ao estágio clínico da doença, 48\% dos pacientes apresentavam-se em fase inicial (estágios I e II) da doença, enquanto $52 \%$, em fase avançada (estágios III e IV).

As informaçôes sobre o hábito de fumar foram obtidas por meio de questionário epidemiológico ${ }^{2}$. Para operacionalização das variáveis sobre o hábito de fumar, foram consideradas as seguintes medidas: idade de início, anos de fumo, número de cigarros por dia, tempo de parada do hábito em anos e carga tabágica, expressa pelo índice maços/ano (obtida multiplicando-se o número de maços de cigarros fumados por dia pelo número de anos de fumo $)^{2}$. Com relação ao hábito de beber, as informações foram obtidas pela aplicaçấo de perguntas sobre o tipo e a quantidade de bebida alcoólica consumida. A ingestâo de álcool, em gramas por dia, foi estimada utilizando o Programa de Apoio à Nutrição do Centro de Informática em Saúde Pública da Escola Paulista de Medicina NutWin, versão 1.5.2.1.

Para avaliação da ingestão alimentar habitual individual no período de seis meses, foi utilizado o questionário de frequência alimentar quantitativo (QFAq). O questionário 
foi formulado e aplicado, sempre pela pesquisadora, durante a entrevista com o paciente. O QFAq é uma modificação existente do Questionário de Frequência Alimentar (QFA), utilizado para avaliar a ingestáo habitual de grupos específicos de alimentos, no qual o indivíduo relata a quantidade dos alimentos ingeridos para se estimar o tamanho das porçóes. No presente estudo, o questionário constou de uma lista que compreendeu o total aproximado de 118 itens de alimentos, preparaçóes e bebidas; sendo cerca de 45 itens referentes ao consumo de hortaliças e frutas. Para cada item alimentar do QFAq, os pacientes referiram a frequência média habitual de consumo, a respectiva unidade de tempo (se por dia, por semana ou por mês) e o tamanho da porção individual usual, em medidas caseiras ou em unidades (pequena, média ou grande). As medidas caseiras descritas pelos pacientes foram convertidas em grama ou mililitro, conforme a tabela de composiçáo de alimentos de Pinheiro et al. ${ }^{2}$ Os dados foram transformados em quantidades de consumo diárias (gramas/dia do alimento) para que se procedesse à análise da ingestấo alimentar, que foi feita usando o cálculo: da quantidade diária de licopeno (Li), luteína/ zeaxantina $(\mathrm{L} / \mathrm{Z})$, betacriptoxantina $(\mathrm{BCr})$, alfacaroteno $(\mathrm{AC})$, betacaroteno $(\mathrm{BC})$, e total dos carotenoides (TC). A ingestáo total de carotenoides obteve-se pela soma das ingestôes dos carotenoides individuais $(\mathrm{Li}+\mathrm{L} / \mathrm{Z}+\mathrm{BCr}+\mathrm{AC}+$ $B C)$. A estimativa da ingestão de carotenoides foi baseada em dados brasileiros de composição alimentar para a maioria dos alimentos ${ }^{2}$. Contudo, outras fontes foram utilizadas para valores de carotenoides não disponíveis, sendo usado, principalmente, o banco de dados mais recente do Departamento de Agricultura dos Estados Unidos 2 . Para calcular a ingestáo alimentar desses nutrientes, os alimentos e seus respectivos teores de carotenoides foram incorporados ao Programa de Apoio à Nutrição do Centro de Informática em Saúde Pública da Escola Paulista de Medicina, NutWin, versão 1.5.2.1. Sendo a gordura importante para absorção dos carotenoides, na lista de frequência de alimentos foram incluídos os alimentos fontes deste macronutriente para estimativa de sua ingestáo habitual. As quantidades referidas em medidas caseiras pelos pacientes foram transformadas em gramas diárias de consumo para cada alimento. Para o cômputo da ingestão de gordura foi multiplicada a frequência de consumo de cada alimento pelo conteúdo de gordura das porçóes específicas, o valor obtido foi dividido por sete dias, obtendo-se, assim, a ingestão diária de gordura proveniente de cada alimento. Estes cálculos foram realizados com o auxílio do NutWin.

As biópsias orais, do tecido normal e neoplásico, foram obtidas durante o ato cirúrgico, sendo os fragmentos de tecidos retirados pelos cirurgióes. O fragmento de tecido normal foi obtido da região contralateral à lesão, na mesma área anatômica. Logo após a retirada, as amostras de tecido oral foram submetidas ao congelamento em nitrogênio líquido. Em seguida, foram congeladas em tubos tipo Eppendorf e armazenadas à temperatura de $-70^{\circ} \mathrm{C}$. As dosagens dos carotenoides foram realizadas aproximadamente seis meses após o último paciente ter sido avaliado. Para extração dos carotenoides do tecido, foi utilizado o método descrito por Handelman et al. ${ }^{2}$ As concentraçóes dos carotenoides foram analisadas utilizando a metodologia por CLAE. Foi utilizado o cromatógrafo Alliance da Waters 2.695 com detector Waters 2.996 - fotodiodo. A coluna utilizada foi a C18, Pecosphere-3, e o comprimento de onda do detector foi fixado em $455 \mathrm{~nm}$.

A estatística descritiva dos dados estudados foi apresentada em tabelas, sendo as variáveis categóricas expressas em porcentagem. As variáveis contínuas com distribuição normal foram expressas em valores médios e desvios-padrão, e as variáveis com distribuição não paramétrica foram apresentadas em valores de mediana e percentis 25 e 75 . O teste t pareado e a Prova de Wilcoxon foram utilizados na comparaçáo de dois grupos dependentes para dados com distribuição normal e não paramétrica, respectivamente. O teste de Kruskal-Wallis foi empregado na comparação entre mais de dois grupos para dados com distribuição não paramétrica; a diferença entre os grupos foi obtida aplicando-se o teste de Dunn. Os coeficientes de correlaçáo de Spearman foram calculados para analisar as inter-relaçóes entre as variáveis contínuas estudadas. Para todos os testes estatísticos, empregou-se o pacote estatístico Sigma Stat for Windows, versão 2.03 (SPSS; Chicago, IL, EUA). A significância dos resultados foi fornecida ao nível de $5 \%$.

\section{RESULTADOS}

Entre os pacientes estudados, 45 foram fumantes e 41 usuários de bebidas alcoólicas. Entre os pacientes fumantes e ex-fumantes, $49 \%$ deles referiram somente uso de cigarro com filtro, 33\% fizeram uso tanto de cigarros com filtro como sem filtro (cigarro de palha ou corda), 16\% somente usaram cigarros de palha ou corda e $2 \%$, cachimbo. Os valores médios e desvios-padrão ou medianos (percentis 25 e 75) das variáveis relacionadas ao hábito de fumar foram: idade de início $16 \pm 6$, anos de fumo $39 \pm 14$, cigarros por dia 10(5-20), e maços/ano 20(12-30). Dos pacientes que consumiam álcool, a ingestão média foi 56 gramas de álcool por dia. Dos usuários e ex-usuários de álcool, 24\% deles referiram consumir apenas cachaça, 59\% referiram uso associado de cachaça e cerveja e $10 \%$ uso associado de cachaça com outras bebidas alcoólicas.

A comparação da proporção de carotenoides individuais na dieta, no soro e nos tecidos orais dos pacientes estudados está registrada na Tabela 1 . O licopeno foi o carotenoide predominante na dieta e no soro, enquanto a luteína/ zeaxantina foi o segundo carotenoide predominante no 
soro e o terceiro na dieta. Nos tecidos, a luteína/zeaxantina representou $64 \%-65 \%$ dos carotenoides totais no tecido oral. Não foram encontradas diferenciaçóes estatísticas entre as proporçôes de licopeno e luteína/zeaxantina presentes no soro e nos tecidos. Também não foram verificadas diferenças estatísticas significantes entre as proporçóes de licopeno e betacaroteno na dieta (Tabela 1 ).

Os valores médios e desvios-padrão ou as medianas e os percentis 25 e 75 da ingestão habitual diária $(\mathrm{mg} / \mathrm{dia})$ de carotenoides sáo apresentados na Tabela 2. Os valores de ingestáo habitual de carotenoides foram menores do que os valores de ingestáo da populaçáo no estudo do NHANES III. Não foram observadas diferenças significativas entre as ingestốes dos carotenoides entre os pacientes do sexo masculino e feminino: licopeno $(\mathrm{p}=0,92)$, luteína/zeaxantina $(\mathrm{p}=0,46)$, betacriptoxantina $(\mathrm{p}=0,19)$, alfacaroteno $(\mathrm{p}=0,87)$, betacaroteno $(\mathrm{p}=0,36)$ e total dos carotenoides $(\mathrm{p}=0,71)$. Quanto à ingestão de gordura, os valores medianos e correspondentes aos percentis 25 e 75 foram 51 (47-61) g de gordura.

Os valores médios e desvios-padrão ou medianos (percentis 25 e 75$)$ das concentraçóes séricas $(\mu \mathrm{mol} / \mathrm{L}$ ) dos carotenoides estáo apresentados na Tabela 3. Os carotenoides presentes em maiores concentraçóes no soro foram o licopeno e a luteína/zeaxantina. Não foram observadas diferenças significativas entre as concentraçóes séricas dos carotenoides entre os pacientes do sexo masculino e feminino: licopeno $(\mathrm{p}=0,46)$, luteína/zeaxantina $(\mathrm{p}=0,40)$, betacriptoxantina $(\mathrm{p}=0,91)$, alfacaroteno $(\mathrm{p}=0,61)$, betacaroteno $(\mathrm{p}=0,36)$ e total dos carotenoides $(p=0,10)$. No tecido oral, a luteínal zeaxantina foi detectada em maiores concentraçôes no tecido normal $(3,49 \pm 2,56 \mu \mathrm{mol} / \mathrm{kg})$, e no tecido neoplásico $(2,90 \pm 2,27 \mu \mathrm{mol} / \mathrm{kg})$. Para o licopeno, verificaram-se concentraçôes similares entre tecido normal $1,13(0,75-$ $1,76) \mu \mathrm{mol} / \mathrm{kg}$ e tecido neoplásico $1,15(0,80-1,90) \mu \mathrm{mol} /$ $\mathrm{kg}$. As concentraçôes de betacriptoxantina, alfacaroteno e betacaroteno no tecido oral normal foram $0,09(0,02-0,31)$ $\mathrm{mmol} / \mathrm{kg}, 0(0-0,12) \mu \mathrm{mol} / \mathrm{kg}, 0,12(0,07-0,19) \mu \mathrm{mol} /$ $\mathrm{kg}$, respectivamente. No tecido oral neoplásico foram: betacriptoxantina $0,09(0-0,24) \mu \mathrm{mol} / \mathrm{kg}$, alfacaroteno 0 $(0-0,11) \mathrm{mmol} / \mathrm{kg}$ e betacaroteno $0,10(0,06-0,25) \mu \mathrm{mol} /$ $\mathrm{kg}$. Não houve diferenças estatísticas significativas entre as concentraçóes de todos os carotenoides na comparação de tecidos normal e neoplásico: licopeno $(\mathrm{p}=0,73)$, luteína/zeaxantina $(\mathrm{p}=0,21)$, betacriptoxantina $(\mathrm{p}=0,61)$, alfacaroteno $(\mathrm{p}=0,52)$ e betacaroteno $(\mathrm{p}=0,34)$.

As correlaçóes positivas e significativas encontradas entre carotenoides dietéticos e séricos foram: licopeno $(r=0,28 ; p \leq 0,05)$, betacriptoxantina $(r=0,41 ; p \leq 0,01)$, alfacaroteno $(\mathrm{r}=0,40 ; \mathrm{p} \leq 0,01)$. A betacriptoxantina $(\mathrm{r}=0,32 ; \mathrm{p} \leq 0,05)$ e o alfacaroteno $(\mathrm{r}=0,54 ; \mathrm{p} \leq 0,001)$ dietéticos também se correlacionaram com suas concentrações no tecido neoplásico. As correlaçóes encontradas entre carotenoides séricos e teciduais (tecido neoplásico) foram: licopeno $(\mathrm{r}=0,46 ; \mathrm{p} \leq 0,0001)$, betacriptoxantina $(\mathrm{r}=0,70 ; \mathrm{p} \leq 0,001)$, alfacaroteno $(\mathrm{r}=0,45 ; \mathrm{p} \leq 0,01)$ e betacaroteno $(\mathrm{r}=0,59 ; \mathrm{p} \leq 0,001)$. As correlaçôes entre tecido normal e tecido neoplásico foram verificadas para o licopeno $(\mathrm{r}=0,29 ; \mathrm{p} \leq 0,05)$, a betacriptoxantina $(r=0,58 ; p \leq 0,001)$, o alfacaroteno $(r=0,52 ; p \leq 0,001)$ e o betacaroteno $(r=0,42 ; p \leq 0,01)$.

\section{DISCUSSÃO}

Conforme o tipo e a quantidade de tabaco utilizado, os tabagistas apresentam probabilidade quatro a 15 vezes maior de desenvolver câncer de boca do que os não tabagistas ${ }^{2}$. No grupo estudado, poucos pacientes (quatro) fumavam entre 30 a 40 cigarros por dia. Apesar de a carga tabágica (anos/maço) ser elevada em indivíduos com câncer, verificou-se nos pacientes estudados carga tabágica não muito elevada. Na população geral, é descrito que a ingestáo diária de quatro doses de bebidas alcoólicas aumenta o risco de câncer oral em três vezes ${ }^{2,3}$. No presente estudo, encontrou-se ingestão diária média de 2,4 doses

Tabela 1. Composição (percentual do valor total) de carotenoides dietéticos, séricos e teciduais orais de pacientes com cânceres da cavidade oral e da orofaringe

\begin{tabular}{|c|c|c|c|c|}
\hline & $\begin{array}{l}\text { Dieta* } \\
(n=46)\end{array}$ & $\begin{array}{l}\text { Soro* } \\
(n=46)\end{array}$ & $\begin{array}{l}\text { Tecido normal* } \\
(n=46)\end{array}$ & $\begin{array}{l}\text { Tecido neoplásico* } \\
(n=46)\end{array}$ \\
\hline $\mathrm{Li}$ & $53(33-65)^{c}$ & $45(36-55)^{b}$ & $25(18-33)^{b}$ & $26(20-36)^{b}$ \\
\hline $\mathrm{L} / \mathrm{Z}$ & $14(7-22)^{b}$ & $28(21-38)^{b}$ & $64(52-73)^{b}$ & $65(49-72)^{b}$ \\
\hline $\mathrm{BCr}$ & $2(1-7)^{a}$ & $9(4-16)^{a}$ & $3(0,3-8)^{a}$ & $3(0-6)^{a}$ \\
\hline$A C$ & $3(1-7)^{a}$ & $4(2-6)^{c}$ & $0(0-3)^{a}$ & $0(0-4)^{a}$ \\
\hline $\mathrm{BC}$ & $26(18-36)^{b c}$ & $7(5-12)^{a}$ & $3(1-5)^{a}$ & $3(1-4)^{a}$ \\
\hline
\end{tabular}

$\mathrm{Li}=$ licopeno; $\mathrm{L} / \mathrm{Z}=$ luteína e zeaxantina; $\mathrm{BCr}$ =betacriptoxantina; $\mathrm{AC}=$ alfacaroteno; $\mathrm{BC}=$ betacaroteno

*Os dados foram expressos como porcentagem (mediana) do total de carotenoides; números em parênteses representam os percentis 25 e 75 . Testes estatísticos usados: Kruskal-Wallis (mediana); comparações das proporçôes de carotenoides em cada grupo (dieta, soro e tecidos): método de Dunn [letras diferentes mostram diferenças significativas $(\mathrm{P}>0,05)]$

Obs.: $\mathrm{n}=46$, uma vez que ocorreram perdas de amostras: uma de tecido normal e uma de tecido neoplásico de pacientes diferentes 
Tabela 2. Valores de ingestão alimentar habitual diária de carotenoides de pacientes com cânceres da cavidade oral e da orofaringe

\begin{tabular}{c|c|c|c|c}
\hline \multirow{2}{*}{$\begin{array}{c}\text { Variáveis } \\
(\mu \mathbf{g} / \text { dia) }\end{array}$} & \multicolumn{3}{|c|}{ Resultados } & $\begin{array}{c}\text { Valores médios* } \\
\text { de referência } \\
\text { NHANES III } \\
(\mu \mathbf{g} / \mathbf{d i a})\end{array}$ \\
\cline { 2 - 5 } & $\begin{array}{c}\text { Homens } \\
\mathbf{n = 3 7}\end{array}$ & $\begin{array}{c}\text { Mulheres } \\
\mathbf{n = 1 1}\end{array}$ & $\begin{array}{c}\text { Total } \\
\mathbf{n}=48\end{array}$ & 9.378 \\
\hline $\mathrm{Li}$ & $2.023(1.032-2.823)$ & $2.500 \pm 2.064$ & $1.994(1.144-3.114)$ & 1.719 \\
\hline $\mathrm{L} / \mathrm{Z}$ & $446(252-786)$ & $713 \pm 488$ & $508(269-848)$ & 145 \\
\hline $\mathrm{BCr}$ & $83(19-326)$ & $23(4,2-214)$ & $78(17-288)$ & - \\
\hline $\mathrm{AC}$ & $107(47-271)$ & $93(42-244)$ & $102(47-265)$ & 1.985 \\
\hline $\mathrm{BC}$ & $1.279 \pm 1.016$ & $1.602 \pm 1.059$ & $1.345 \pm 1.013$ & - \\
\hline $\mathrm{TC}$ & $3.469(2.371-6.728)$ & $5.139 \pm 3.526$ & $3.859(2.565-7.266)$ & \\
\hline
\end{tabular}

Os valores são apresentados na forma de médias e desvios-padrão, e medianas e percentis 25 e 75 . Li=licopeno; L/Z=luteína e zeaxantina; $\mathrm{BCr}=$ betacriptoxantina; $\mathrm{AC}=$ alfacaroteno; $\mathrm{BC}=$ betacaroteno; $\mathrm{TC}=$ total dos carotenoides $(\mathrm{Li}+\mathrm{L} / \mathrm{Z}+\mathrm{BCr}+\mathrm{AC}+\mathrm{BC}) ;-$ = sem dado.

*Valores médios (ingestão habitual) de todos indivíduos, independente do sexo e da faixa etária (NHANES III, 1988-1994); fonte: Institute of Medicine (IOM)

Tabela 3. Valores séricos de carotenoides de pacientes com cânceres da cavidade oral e da orofaringe

\begin{tabular}{|c|c|c|c|c|}
\hline \multirow{2}{*}{$\begin{array}{l}\text { Variáveis } \\
\text { ( } \mu \mathrm{mol} / \mathrm{L} \text { ) }\end{array}$} & \multicolumn{3}{|c|}{ Resultados } & \multirow{2}{*}{$\begin{array}{l}\text { Valores médios* } \\
\text { de referência } \\
\text { NHANES III } \\
(\mu \mathrm{mol} / \mathrm{L})\end{array}$} \\
\hline & $\begin{array}{c}\text { Homens } \\
n=37\end{array}$ & $\begin{array}{c}\text { Mulheres } \\
\mathbf{n = 1 1}\end{array}$ & $\begin{array}{c}\text { Total } \\
n=48\end{array}$ & \\
\hline $\mathrm{Li}$ & $0,56 \pm 0,31$ & $0,48 \pm 0,33$ & $0,54 \pm 0,32$ & 0,44 \\
\hline $\mathrm{L} / \mathrm{Z}$ & $0,31(0,28-0,35)$ & $0,33 \pm 0,05$ & $0,31(0,28-0,36)$ & 0,37 \\
\hline $\mathrm{BCr}$ & $0,09(0,04-0,16)$ & $0,08(0,06-0,13)$ & $0,09(0,05-0,16)$ & 0,17 \\
\hline$A C$ & $0,04(0,02-0,06)$ & $0,06 \pm 0,05$ & $0,04(0,02-0,07)$ & 0,09 \\
\hline $\mathrm{BC}$ & $0,07(0,05-0,10)$ & $0,21 \pm 0,21$ & $0,09(0,05-0,13)$ & 0,35 \\
\hline
\end{tabular}

Os valores são apresentados na forma de médias e desvios-padrão, e medianas e percentis 25 e 75 . Li=licopeno; L/Z=luteína e zeaxantina; BCr=betacriptoxantina; $\mathrm{AC}=$ alfacaroteno; $\mathrm{BC}=$ betacaroteno

*Valores médios de todos indivíduos, independente do sexo e da faixa etária (NHANES III, 1988-1994) transformados de mg/dL para mmol/L; fonte: Institute of Medicine (IOM)

ou 60 gramas de álcool. As relaçóes entre fumo, álcool e carotenoides podem refletir o efeito específico do fumo ou álcool sobre o carotenoide, o próprio padrão alimentar do indivíduo, ou a combinação destes fatores ${ }^{4}$.

Em seres humanos, maiores concentraçóes de licopeno são encontradas nos testículos, nas glândulas adrenais e no fígado, em comparação às concentrações em outros órgãos ${ }^{2}$. Na próstata, o licopeno predomina ${ }^{5}$; a zeaxantina e a luteína/zeaxantina estão presentes em maiores proporçóes no tecido adiposo, ovário e pigmento macular 5 . No presente trabalho, o licopeno foi o carotenoide predominante na dieta ingerida e no soro; entretanto, foi o segundo carotenoide no tecido oral em termos de concentração (Tabela 1). El-Sohemy et al. ${ }^{6}$ também observaram que o licopeno foi o carotenoide abundante na dieta e no sangue e, apesar disso, foi o menos abundante no tecido adiposo. Portanto, observa-se que a concentração tecidual de licopeno náo mantém em todos os tecidos a proporção em relaçáo às concentraçôes na dieta e no soro. Quanto à distribuição dos carotenoides, no tecido oral, não foram verificadas diferenças estatísticas entre os carotenoides predominantes no tecido normal (luteína/ zeaxantina $64 \%$ e licopeno $25 \%$ ) e no tecido neoplásico (luteína/zeaxantina $65 \%$ versus licopeno $26 \%$ ) (Tabela 1). Este achado permite sugerir que há maior consumo no tecido, visando à proteçâo antioxidante, ou menor taxa de captação tecidual de licopeno, ou, por outro lado, captação seletiva ou acúmulo de luteína/zeaxantina no tecido ${ }^{6,7}$.

O World Cancer Research Fund/American Institute for Cancer Research recomenda, como nível prudente para a prevenção do câncer, aproximadamente 9.000 a $18.000 \mathrm{mg} /$ dia de carotenoides dietéticos ${ }^{8}$. No presente estudo, o grupo de pacientes apresentou valor mediano de ingestão total de carotenoides inferior à recomendada $(3.859 \mathrm{mg} /$ dia). Em relação ao licopeno, o valor de $35.000 \mathrm{mg} /$ dia é sugerido como ingestáo média diária apropriada deste nutriente para proteção antioxidante ${ }^{2}$. Com base neste nível, os pacientes estudados apresentaram valores de ingestáo de licopeno expressivamente diminuídos.

Por outro lado, o estudo amplo do United States Third National Health and Nutrition Examination Survey (NHANES III, 1988-1994) ${ }^{1}$ tem sido utilizado como 
dado populacional de referência para o consumo de carotenoides. Dessa maneira, os valores de ingestão verificados no presente estudo são menores dos que os valores médios relatados pelo NHANES III (Tabela 2). Em relação ao licopeno, foi observada elevada frequência de pacientes $(44 \%)$ cuja ingestão habitual diária estava abaixo do quinto percentil do NHANES III. A ingestão alimentar diminuída de carotenoides pode estar associada à própria doença, por interferência na mastigação e deglutição dos alimentos, bem como pela anorexia'. Nesse contexto, note-se ter sido verificada desnutriçáo energético-proteica em $37 \%$ dos pacientes estudados ${ }^{2}$. Outro fator que pode ter contribuído para a reduzida ingestão de carotenoides é a má qualidade da dieta entre os alcoolistas crônicos e indivíduos fumantes.

Com relação à disponibilidade domiciliar per capita de carotenoides na populaçâo brasileira, Padovani ${ }^{10}$ verificou que os valores de ingestáo do licopeno variaram de $530 \mathrm{mg} /$ dia a $2.760 \mathrm{mg} /$ dia para as famílias residentes nos diferentes estratos de renda, na região metropolitana de São Paulo. Assim, o valor mediano da ingestáo do grupo de pacientes com câncer estudado $(1.994 \mathrm{mg} / \mathrm{dia})$ esteve dentro da faixa de variação média observada por Padovani ${ }^{10}$. O mesmo pôde ser constatado com os outros carotenoides.

A ingestão de licopeno pelos pacientes estudados foi semelhante aos valores de ingestão encontrados em outros estudos, em indivíduos com esse tipo de câncer. Schantz et al. ${ }^{11}$, estudando pacientes com câncer de cabeça e pescoço (não previamente tratado) verificaram que 69\% deles tinham ingestão de licopeno inferior a $1.898 \mu \mathrm{g} /$ dia. Destes pacientes, 53\% apresentavam câncer oral. Mayne $e t$ al. ${ }^{4}$ verificaram, em pacientes com cânceres de cavidade oral, faringe e laringe, já tratados, valor mediano de ingestão de licopeno de $1.290 \mu \mathrm{g} / \mathrm{dia}$, enquanto Steward et al. ${ }^{12}$ encontraram valor médio de $4.225 \mathrm{mg} / \mathrm{dia}$.

As concentraçóes séricas de carotenoides em populaçóes ocidentais variam de $0,29-0,60 \mu \mathrm{mol} / \mathrm{L}$ para o licopeno, $0,28-0,52 \mu \mathrm{mol} / \mathrm{L}$ para o betacaroteno e $0,2-0,28 \mu \mathrm{mol} / \mathrm{L}$ para a luteína ${ }^{2}$. Quando se confrontaram os valores das concentrações séricas de carotenoides no grupo estudado com os dados da população do NHANES III, o valor médio da concentração sérica de licopeno revelou-se superior ao valor médio da populaçáo norte-americana. Com relaçáo aos outros carotenoides, valores séricos de luteína/zeaxantina, betacriptoxantina e alfacaroteno foram ligeiramente inferiores, enquanto o valor de betacaroteno estava acentuadamente diminuído.

Em indivíduos com câncer de vários órgãos, Abiaka et al. ${ }^{13}$ observaram concentraçôes séricas de licopeno variando de 0,12 a $1,55 \mu \mathrm{mol} / \mathrm{L}$, e as de betacaroteno, de 0,18 a $0,76 \mu \mathrm{mol} / \mathrm{L}$. Esses autores, ao comparar os valores séricos de licopeno de pacientes com câncer oral e controles, observaram valor significativamente maior $(1,55 \mu \mathrm{mol} / \mathrm{L})$ nos pacientes do que nos indivíduos do grupo controle $(0,72 \mu \mathrm{mol} / \mathrm{L})$.
Mayne $e t a l .^{4}$, estudando indivíduos já tratados por cânceres de cavidade oral, faringe e laringe, verificaram valor médio de licopeno no sangue de $0,59 \mu \mathrm{mol} / \mathrm{L}$. No presente trabalho, o valor médio de licopeno encontrado $(0,54 \mu \mathrm{mol} / \mathrm{L})$ esteve muito próximo ao verificado no estudo de Mayne et al. ${ }^{4}$; porém foi inferior aos valores obtidos por Abiaka et $a l .{ }^{13}$, tanto em relação ao grupo de indivíduos com câncer oral como em relaçáo ao grupo de indivíduos do grupo controle.

Pela falta de dados disponíveis para interpretar os valores de carotenoides encontrados no tecido oral do grupo estudado, foram confrontados os resultados com os valores observados em outros tecidos de seres humanos. Desse modo, foi observado que o valor médio de luteína/ zeaxantina encontrado no tecido oral $(2,90-3,49 \mu \mathrm{mol} / \mathrm{kg})$ esteve acima do verificado no tecido adiposo $(1,71 \mu \mathrm{mol} / \mathrm{kg}$ em homens; $2,25 \mu \mathrm{mol} / \mathrm{kg}$ em mulheres) por El-Sohemy et al. ${ }^{6} \mathrm{em}$ 531 indivíduos controles, participantes de estudo casocontrole sobre dieta e doença cardíaca na Costa Rica.

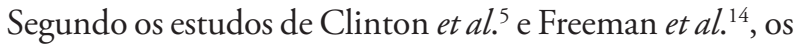
valores médios de luteína no tecido normal da próstata são $0,26 \mu \mathrm{mol} / \mathrm{kg} \mathrm{e} 0,37 \mu \mathrm{mol} / \mathrm{kg}$, respectivamente, resultados, entretanto, que se referem à concentração conjunta de luteína e zeaxantina. No presente trabalho, a luteína/ zeaxantina foi, entre os carotenoides estudados, aquela detectada em maior concentraçáo no tecido oral.

Em outros tecidos de seres humanos, foi observada faixa de concentração média de licopeno de $0,12-0,80 \mu \mathrm{mol} /$ $\mathrm{kg}$ na próstata ${ }^{5,14}$, de $0,20-1,30 \mu \mathrm{mol} / \mathrm{kg}$ no tecido adiposo $^{6,15}$, e de $0,017-0,31 \mu \mathrm{mol} / \mathrm{kg}$ no cólon ${ }^{16,17}$. Assim, verificou-se que a concentraçáo tecidual oral de licopeno do grupo de pacientes estudado foi próxima às concentraçóes de licopeno reportadas no tecido da próstata por Clinton et al. ${ }^{5}$ e no tecido adiposo por Kaplan et al. ${ }^{2} \mathrm{e}$ maior do que os valores observados no cólon por Nierenberg \& Nann ${ }^{16}$ e Pappalardo et al. ${ }^{17}$. Quanto ao betacaroteno, observou-se, no grupo estudado, concentração tecidual oral diminuída $(0,12 \mu \mathrm{mol} / \mathrm{kg})$ em relaçáo à observada em outros tecidos, como no tecido adiposo de indivíduos controles $(0,37 \mu \mathrm{mol} / \mathrm{kg}$ em homens; $0,76 \mu \mathrm{mol} / \mathrm{kg} \mathrm{em}$ mulheres $)^{6}$, e no tecido normal da próstata $(0,48 \mu \mathrm{mol} / \mathrm{kg})^{5} \mathrm{e}$ $(0,24 \mu \mathrm{mol} / \mathrm{kg})^{14}$. Um dos fatores que pode ter influenciado a concentraçáo de betacaroteno no tecido oral, em nosso estudo, é a alimentação.

Quanto à comparação da concentração de carotenoides em tecidos neoplásicos e não neoplásicos, os resultados publicados não são consistentes. Clinton et al. ${ }^{5}$ observaram maiores concentraçóes de carotenoides no tecido neoplásico da próstata. Entretanto, menores concentraçôes teciduais de carotenoides foram relatadas em tecido neoplásico de cólon ${ }^{17}$, estômago ${ }^{7}$ e em adenoma colorretal $^{18}$. A menor concentração de carotenoides em tecido neoplásico sugere aumento da degradação neste tecido, com consequente depleção tecidual ${ }^{7,17}$. $\mathrm{O}$ aumento da degradaçáo de carotenoides, no tecido 
neoplásico, pode ser compensado pela maior captação, por este tecido, de carotenoides circulantes provenientes da alimentação. Neste contexto, Paiva et al. ${ }^{7}$, apesar de verificarem aumento da degradaçáo de betacaroteno no tecido neoplásico gástrico, não encontraram diferença significativa da sua concentração, quando comparados os tecidos neoplásico e não neoplásico. No presente estudo, não foi verificada diferença estatística significante entre os valores teciduais de carotenoides na comparação de tecido normal com o tecido neoplásico. Este achado pode ter sido devido ao fato de as variáveis envolvidas apresentarem variabilidade bastante acentuada.

Vários estudos relatam correlaçôes significativas, consideradas modestas, entre os valores da concentraçáo sanguínea e da ingestão de carotenoides ${ }^{4}$, sendo isto também encontrado neste estudo. Esses níveis de valores das correlaçóes entre os valores da ingestão e as concentraçôes séricas de carotenoides podem depender da influência de vários fatores, como a variação da biodisponibilidade entre as fontes alimentares de carotenoides, a diferença de absorção devida à composição da dieta e a estimativa errônea da ingestáo alimentar ${ }^{1}$. Em oposição, tem sido descrita a ausência de associaçáo entre a ingestão dietética e a concentração tecidual de carotenoides, como verificado para o licopeno em relação à concentração tecidual da próstata ${ }^{14}$, do tecido adiposo da mama $^{15}$ e de células da mucosa bucal ${ }^{2}$. Semelhantemente, verificou-se que as ingestóes dietéticas de licopeno, luteína/ zeaxantina e betacaroteno não se correlacionaram com suas concentrações no tecido oral.

Enquanto os métodos de avaliação do consumo alimentar - Recordatório de 24 horas e Registro Alimentar - podem ser utilizados em qualquer população sem maiores problemas, os QFAs devem ser validados em função da população a ser avaliada, pois a inclusão ou a exclusão de itens de consumo frequente podem afetar o instrumento, porém existem poucos estudos publicados de reprodutibilidade e validade dos instrumentos que avaliam o consumo de alimentos. Uma limitação do presente estudo foi a não utilizaçáo de um QFA validado para estimativa da ingestáo de carotenoides; porém foram verificadas correlaçóes positivas e significativas entre carotenoides dietéticos, séricos e teciduais. Em 2006, Matarazzo et al. ${ }^{19}$, avaliando a reprodutibilidade e a validade do Questionário de Frequência do Consumo Alimentar utilizado no Estudo Latino-Americano sobre câncer oral e de laringe, observaram que o mesmo superestimou moderadamente o consumo de alguns grupos de alimentos, como os das frutas e hortaliças, que contribuem significativamente para a ingestão dos carotenoides dietéticos. Esses autores concluíram que o instrumento testado apresentou razoável validade.

\section{CONCLUSÕES}

No grupo de pacientes estudados pôde-se concluir que: 1) a luteína/zeaxantina e o licopeno representaram juntos cerca de $90 \%$ dos carotenoides do tecido oral, não apresentando diferença estatística entre si quando se comparou a proporcionalidade da distribuição em ambos os tecidos (normal e neoplásico); 2) a ingestáo habitual de carotenoides foi inferior aos níveis "prudentes" de ingestáo, e menores do que os valores de ingestấo da população no estudo do NHANES III, porém dentro da variação média encontrada na população brasileira; 3) a ingestão de licopeno também foi semelhante aos valores encontrados em indivíduos com câncer; 4) a concentração sérica de carotenoides foi superior para o licopeno, e diminuída para o betacaroteno, quando se comparou com os dados da população norte-americana de estudo do NHANES III; 5) a concentração sérica de licopeno também foi próxima ou inferior aos valores encontrados em indivíduos já tratados por câncer ou com câncer; 6) os carotenoides sem atividade de vitamina A luteína/zeaxantina e licopeno - apresentaram concentraçóes elevadas no tecido oral; 7) não foi encontrada depleção de carotenoides na comparação de tecidos neoplásico e normal do mesmo indivíduo; e 8) valores de correlação mais elevados foram observados entre os carotenoides do soro e tecido oral neoplásico do que com a ingestão dietética.

Neste estudo, foi verificado que o tecido oral contém predominantemente luteína/zeaxantina; contudo, porém, não está determinado se isto poderia explicar o risco reduzido de câncer oral associado com o consumo de alimentos ricos em luteína/zeaxantina presente em grande variedade de hortaliças e frutas. O presente estudo traz contribuiçóes para o conhecimento do estado dos carotenoides em tecido neoplásico e tecido normal exposto a agentes pró-carcinogênicos, como é o tecido oral. Entretanto, o papel dos carotenoides, no seu relacionamento com o câncer oral, necessita, sob o ponto de vista do seu possível papel protetor, de investigaçóes adicionais neste tipo de populaçáo.

\section{AGRADECIMENTOS}

Ao CNPq e à FAPESP pelo apoio financeiro. Aos cirurgiōes Guilherme A. Cestari Filho, Antonio F. Bortolucci, João F. Neto, Afonso do C. Javaroni e José V. Tagliarini, pelo gentil encaminhamento dos pacientes. Ao Hospital Amaral Carvalho e à Faculdade de Medicina de Botucatu, que viabilizaram a realização deste estudo.

\section{Declaração de Conflito de Interesses: Nada a Declarar}

\section{REFERÊNCIAS}

1. Institute of Medicine (IOM). Dietary Reference Intakes for vitamin C, vitamin E, Selenium, and Carotenoids. 
[acesso em jun 2008]. Disponível em: < http://www.nap. edu/openbook>

2. Maio R. Fatores determinantes da concentração de licopeno no tecido oral neoplásico em pacientes com cânceres da cavidade oral e da orofaringe. [tese]. Botucatu (SP): Universidade Estadual Paulista; 2005.

3. Carrard VC, Pires AS, Paiva RL, Chaves ACM, Sant'Ana Filho M. Álcool e câncer bucal: consideraçôes sobre os mecanismos relacionados. Revista brasileira de cancerologia 2008; 54:49-56.

4. Mayne ST, Cartmel B, Silva F, Kim CS, Fallon BG, Briskin K, et al. Plasma lycopene concentrations in humans are determined by lycopene intake, plasma cholesterol concentrations and selected demographic factors. J Nutr 1999;129: 849-54.

5. Clinton SK, Emenhiser C, Schwartz SJ, Bostwick DG, Williams AW, Moore BJ, et al. Cis-trans lycopene isomers, carotenoids, and retinol in the human prostate. Cancer Epidemiol Biomarkers Prev 1996; 5:823-33.

6. El-Sohemy A, Baylin A, Kabagambe E, Ascherio A, Spiegelman D, Campos H. Individual carotenoid concentrations in adipose tissue and plasma as biomarkers of dietary intake. Am J Clin Nutr 2002;76(1):172-9.

7. Paiva SAR, Yeum KJ, Lee KS, Park IS, Lee-Kim YC, Russel RM. Endogenous carotenoid concentrations in cancerous and non-cancerous tissues of gastric cancer patients in Korea. Asia Pacific J Clin Nutr 1999; 8:160-6.

8. World Cancer Research Fund/American Institute for Cancer Research (WCRF/AICR). Food, nutrition and prevention of cancer: A global perspective. Menasha, WI: BANTA Book group; 1997.

9. Maio R, Tagliarini JV, Burini RC. Implicações nutricionais protéico-energéticas da presença e/ou tratamento dos cânceres de cabeça e pescoço. Rev Bras Otorrinolaringol 2000;66:673-8.

10. Padovani RM. Disponibilidade de carotenóides em relação à energia e proteínas nos domicílios de famílias das regiôes metropolitanas brasileiras. [dissertação]. Campinas-SP: Universidade Estadual de Campinas; 2003.
11. Schantz SP, Zhang Z-F, Spitz MS, Sum M, Hsu TC. Genetic susceptibility to head and neck cancer: interaction between nutrition and mutagen sensitivity. Laryngoscope 1997;107:765-81.

12. Steward DL, Wiener F, Gleich LL, Falciglia G. Dietary antioxidant intake in patients at risk for second primary cancer. Laryngoscope 2003; 113:1487-93.

13. Abiaka CD, Al-Awadi FM, Al-Sayer H, Gulshan S, Behbehani A, Farghaly M. Plasma micronutrient antioxidants in cancer patients. Cancer Detec Prev 2001; 25: 245-53.

14. Freeman VL, Meydani M, Yong S, Pyle J, Wan Y, Arvizu-Durazo R, et al. Prostatic levels of tocopherols, carotenoids, and retinol in relation to plasma levels and self-reported usual dietary intake. Am J Epidemiol 2000 Jan;151:109-18.

15. Zhang S, Tang G, Russell RM, Maysel KA, Stampfer MJ, Willett WC, et al. Mesurement of retinoids and carotenoids in breast adipose tissue and a comparison of concentrations in breast cancer cases and control subjects. Am J Clin Nutr 1997;66: 626-32.

16. Nierenberg DW, Nann SL. A method for determining concentration of retinal, tocopherol, and five carotenoids in human plasma and tissue samples. Am J Clin Nutr 1992;56:417-26.

17. Pappalardo G, Maiani G, Mobarhan S, Guadalaxara A, Azzini E, Raguzzini A, et al. Plasma (carotenoids, retinol, alpha-tocopherol) and tissue (carotenoids) levels after supplementation with beta-carotene in subjects with precancerous and cancerous lesions of sigmoid colon. Eur J Clin Nutr 1997Oct;51(10):661-6.

18. Muhlhofer A, Buhler-Ritter B, Frank J, Zoller WG, Merkle P, Bosse A, et al. Carotenoids are decreased in biopsies from colorectal adenomas. Clin Nutr 2003; 22:65-70.

19. Matarazzo HCZ, Marchioni DML, Fiqueiredo RAO, Slater B, Eluf Neto J, Wünsch Filho V. Reprodutibilidade e validade do questionário de freqüência de consumo alimentar utilizado em estudo caso-controle de câncer oral. Revista brasileira de epidemiologia 2006;9(3):31624. 


\section{Abstract}

The aim of this article is to characterize a group of patients with oral cavity and oropharyngeal cancer in regard to their dietary intake, as well as serum and oral tissue concentrations of carotenoids. A transversal study was undertaken with 37 male and 11 female patients, aging from 39 to 77, without previous treatment for the disease. Oral biopsies were taken during surgery in all patients. Tissue determination of carotenoids was done by High Performance Liquid Chromatography (HPLC) using C18 columns. It was verified that the habitual daily dietary intakes of carotenoids

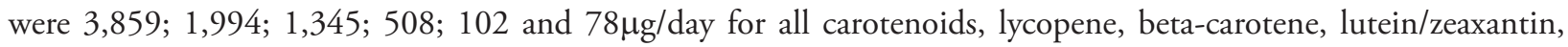
alpha-carotene and beta-cryptoxanthin, respectively. The largest concentrations of carotenoids in the serum were verified for lycopene $(0.54 \mu \mathrm{mol} / \mathrm{L})$ and lutein/zeaxantin $(0.31 \mu \mathrm{mol} / \mathrm{L})$. In the normal tissue, concentrations were $3.49 ; 1.15 ; 0.12$ and $0.09 \mu \mathrm{mol} / \mathrm{kg}$ for lutein/zeaxantin, lycopene, beta-carotene and beta-cryptoxanthin, respectively. These figures were not statistically different from neoplastic tissues. Lycopene was the predominant carotenoid in the $\operatorname{diet}(53 \%)$ and serum (45\%), whereas in the tissues it was lutein/zeaxantin (64-65\%). Significant correlations ( $\mathrm{r}=0.28$ to $\mathrm{r}=0.70$ ) between the amount of carotenoids in the diet, in the serum and in the oral tissue were observed for the majority of the carotenoids. Lycopene was identified as the main carotenoid in the diet and in the serum, whereas lutein/zeaxantin was predominant in the oral tissue. No depletion was observed in carotenoids investigated in the neoplastic tissue in the studied group.

Key words: Carotenoids; Tissues; Mouth Mucosa; Mouth Neoplasms; Eating; Cross-Sectional Studies

\section{Resumen}

Con el objetivo de caracterizar pacientes con cáncer de cavidad bucal y orofaringe, en cuanto a la ingesta alimentar y concentraciones de carotenoides en el suero y tejido bucal, se llevó a cabo un estudio transversal implicando 37 pacientes hombres y 11 mujeres, de edades comprendidas entre 39 y 77 años, sin tratamiento previo de la enfermedad. Las biopsias en la cavidad bucal se lograron durante la cirugía en todos los pacientes. La determinación tisular de carotenoides fue realizada por Cromatografía Líquida de Alta Eficiencia (HPLC), utilizando la columna C18. Las ingestas habituales

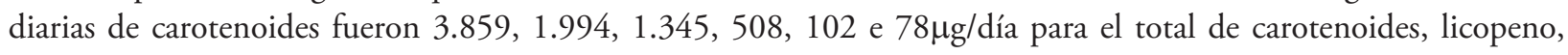
betacaroteno, luteína/zeaxantina, alfacaroteno y betacriptoxantina, respectivamente. Las mayores concentraciones de carotenoides en el suero fueron observadas para el licopeno $(0,54 \mu \mathrm{mol} / \mathrm{L})$ y para la luteína/zeaxantina $(0,31 \mu \mathrm{mol} / \mathrm{L})$. En el tejido normal, las concentraciones encontradas fueron 3,49; 1,15; 0,12 e 0,09 $\mu \mathrm{mol} / \mathrm{kg}$ para la luteína/zeaxantina, el licopeno, el betacaroteno y la betacriptoxantina, respectivamente; esos valores no fueron estadísticamente diferentes en relación a los del tejido neoplásico. El licopeno fue el carotenoide predominante en la dieta (53\%) y en el suero (45\%). En los tejidos, hubo un predominio de la luteína/zeaxantina (64-65\%). Correlaciones significativas ( $\mathrm{r}=0,28$ a r $=0,70$ ), entre los valores de carotenoides en la dieta, en el suero y tejido bucal fueron observadas en la mayoría de los carotenoides. El licopeno fue identificado como el principal carotenoide en la dieta y en el suero, en cambio la luteína/zeaxantina predominó en el tejido bucal. No se observó agotamiento de los carotenoides investigados en el tejido bucal neoplásico del grupo estudiado.

Palabras clave: Carotenóides; Tejidos; Mucosa Bucal; Neoplasias de la Boca; Ingestión de Alimentos; Estudios Transversales 